\title{
ASSESSMENT OF HYDROCARBON SEEPAGE ON FORT PECK RESERVATION, NORTHEAST MONTANA: A COMPARISON OF SURFACE EXPLORATION TECHNIQUES
}

Semi-Annual Report June 28, 2002

By:

Lawrence M. Monson

Work Performed Under Contract No. DE-FG26-00BC15192

Date Published: September 2002
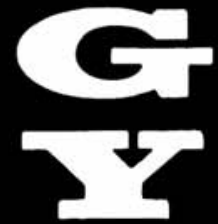

Assiniboine and Sioux Tribes

Poplar, Montana

National Energy Technology Laboratory National Petroleum Technology Office U.S. DEPARTMENT OF ENERGY Tulsa, Oklahoma 


\section{DISCLAIMER}

This report was prepared as an account of work sponsored by an agency of the United States Government. Neither the United States Government nor any agency thereof, nor any of their employees, makes any warranty, expressed or implied, or assumes any legal liability or responsibility for the accuracy, completeness, or usefulness of any information, apparatus, product, or process disclosed, or represents that its use would not infringe privately owned rights. Reference herein to any specific commercial product, process, or service by trade name, trademark, manufacturer, or otherwise does not necessarily constitute or imply its endorsement, recommendation, or favoring by the United States Government or any agency thereof. The views and opinions of authors expressed herein do not necessarily state or reflect those of the United States Government.

This report has been reproduced directly from the best available copy. 
$\mathrm{DOE} / \mathrm{BC} / 15192-3$

Distribution Category UC-122

Assessment of Hydrocarbon Seepage on Fort Peck Reservation, Northeast Montana: A Comparison of Surface Exploration Techniques

By

Lawrence M. Monson

September 2002

Work Performed Under DE-FG26-00BC15192

Prepared for

U.S. Department of Energy

Assistant Secretary for Fossil Energy

Virginia Weyland, Project Manager

U.S. Department of Energy

National Energy Technology Laboratory

National Petroleum Technology Office

One West Third Street, Suite 1400

Tulsa, OK 74103

Prepared by

Assiniboine and Sioux Tribes

Fort Peck Reservation

P.O. Box 1027

Poplar, MT 59255 


\section{Table Of Contents}

Abstract

Introduction $\quad 1$

Background 2

Surface Exploration Techniques 2

Techniques Employed 2

Palomino Oil Field $\quad 3$

Wicape Prospect Area $\quad 3$

Smoke Creek Area $\quad 4$

Summary $\quad 5$

Hydrocarbon Flux Sources $\quad 5$

Conclusions $\quad 5$

References Cited $\quad 6$

$\begin{array}{lr}\text { Figure Captions } & 7\end{array}$ 



\section{A B S TRACT}

Surface exploration techniques have been employed in separate study areas on the Fort Peck Reservation in northeastern Montana. Anomalies associated with hydrocarbon seepage are documented in all three areas and a variety of surface exploration techniques can be compared. In a small area with established production, head gas and thermal desorption methods best match production; other methods also mapped depletion. In a moderate-size area that has prospects defined by 3D seismic data, head gas along with microbial, iodine, and Eh soil anomalies are all associated with the best hydrocarbon prospect. In a large area that contains many curvilinear patterns observed on Landsat images, results are preliminary. Reconnaissance mapping of magnetic susceptibility has identified a potential prospect; subsequent soil gas and head gas surveys suggest hydrocarbon potential. All work was done under DOE Contract \#DE-FG2600BC15192.

\section{INTRODUCTION}

Oil and gas have been produced on the Fort Peck Indian Reservation for fifty years. Located in northeastern Montana (Figure 1), the reservation lies on the western margin of the Williston Basin. Paleozoic formations that are prolific throughout the basin are also the main productive reservoirs on the reservation.

\section{(Figure 1)}

The Fort Peck Tribes have been actively engaged in exploration and production activity during the past ten to fifteen years. As a part of this on-going effort, data sets have been built and prospects have been generated. A recent grant from the United States Department of Energy has provided an opportunity to assess the utility of surface exploration technology in prospect characterization.

The primary objective of the DOE grant is to conduct surface geochemical and nonseismic, geophysical sampling of soils above geologic or geophysical anomalies that have hydrocarbon potential. Sampling programs were carried out on Tribal lands in a phased approach. During the initial phase, hydrocarbon detection methods and study areas were identified and assessed. Subsequently, the selected detection methods were applied in a series of progressively larger and more complex study areas. 


\section{B A C K G R O U D}

The Fort Peck Tribes have established and maintained an extensive petroleum database for the reservation. Well files for approximately 1200 wells are stored as paper copies, on microfiche, and in digital formats. Stratigraphic and structural contour maps have been prepared for a variety of geologic formations. About 950 miles of 2D seismic data have been acquired and exist on Mylar profiles, $16 \mathrm{~mm}$ tape, and CD-ROM. Ten seismic time horizons have been digitized. A number of 3D seismic surveys have been carried out by companies to delineate specific prospects. In addition, aeromagnetic, gravity, and airborne radiometric data are stored in-house, as well as a variety of themes that can be handled with a geographic information system (GIS). A global positioning system (GPS) is available for mapping specific field locations. All of the digital databases are housed in a SUN Ultra 10 server and are manipulated by GeoGraphix Exploration System and ESRI ArcInfo and ArcView software.

Three study areas were selected from a group of more than a dozen candidate areas. Reservation-wide databases were employed in the selection process. (See Figure 1 for area locations.) Subsequently, more detailed local data sets were extracted and displayed to characterize three final study areas. The final three study areas were chosen to represent a spectrum of characteristics, so that work progressed in a phased approach through the three areas. Initial work was done in the Palomino Oil Field. This small area has well-established production that provides a test of utility for the various surface exploration techniques. The Wicape Prospect Area is an intermediate-sized area. Although it has no established production, this area does have well-documented 3D seismic structures that are prospects with excellent potential. The largest study area is the Smoke Creek Area which has a variety of anomalies documented by stratigraphy, structure, geophysics, and remote sensing. Some of these anomalies have potential to be hydrocarbon prospects that are best characterized as "wildcats". As work progressed from the small area with established production to the large area with wildcat potential, a variety of surface exploration techniques were employed and compared.

\section{SURFACE EXPLORATION TECHNIQUES}

To achieve the goal of comparing a variety of surface exploration techniques, a number of independent sub-contractors were employed. Tribal personnel collected all of the soil samples in the field, which were then sent to the respective labs for analysis. All analytical sub-contractors provided data tables and some provided statistical analyses and/or maps. Tribal personnel prepared full-color, computer-contoured maps for all of the data sets. Descriptions of the field operations and analytical procedures are available in Monson (2000). Complete sets of data maps in each of the three study areas are compiled in Monson (2001 and 2002).

\section{Techniques Employed}

The surface exploration techniques employed in the three study areas are summarized in Table 1. Direct techniques measure hydrocarbon gases that have been liberated from soil particles or that are in the soil atmosphere between the particles. In contrast, indirect techniques measure a variety of proxy indicators that theoretically are related to the distribution of hydrocarbon gases. When gases migrate vertically along microseeps or macroseeps, geochemical changes occur in the mineralogy of the surface soils. The resulting surface signatures are thus the tops of diagenetic "chimneys" that are rooted in a subsurface oil accumulation.

Monson, Shurr: 2002

page 3 
Sample depths (Table 1) generally reflect the sampling procedures employed. Shallow soil samples were collected from spade holes. Deeper samples were collected with a power auger or a driven steel pipe. Soil sample containers included steel cans, glass jars, paper envelopes, and plastic bags. Soil sample quantities ranged from about 30 to 625 grams. Soil gas quantities of 5 cubic centimeters were sampled in a syringe.

\section{(Figures 2, 3, 4 and Table 1)}

\section{Palomino Oil Field}

The Palomino Oil Field is an area of current oil production from the Nisku Formation (Devonian). This six-well field was discovered in 1980 and has an estimated ultimate recovery of 2.8 million barrels (Monson, 1995). Production is dominated by the Tribal-Bird 1-7, which has produced 1.4 million barrels. The field is located on a structural high (Figure 2) that is elongate to the northeast and that is perpendicular to a northwest-trending low. The northwest trend corresponds with the margin of a regional Landsat lineament zone marking paleotectonic basement blocks (Shurr and Monson, 1995). Four intersecting traverses that contain 27 collection points form the basis for the surface exploration studies.

Data maps for two direct techniques in the Palomino Field are shown in Figure 3. Propane values are contoured because they display patterns similar to other hydrocarbon data reported for the various direct techniques. Head gas propane patterns correspond extremely well with the oil production (Figure 3-A) and are elongate northeast over the structural high (Figure 2). Acid extract propane patterns show the same northeast orientation (Figure 3-B), but the low values indicate depletion over the areas of production. Thermal desorption propane patterns have a partial correlation with production and soil gas propane patterns also show depletion over areas of production. UV soil fluorescence maps show some possible correlation with production, but are subject to contamination problems from faulting. Many of the direct data maps show northwest linear trends that parallel the regional structural grain.

Data maps for two indirect techniques are shown in Figure 4. Soil microbe patterns generally show low values near production, but an area of high values within the field may mark an in-fill drilling location (Figure 4-A). Iodine patterns show a northeast-trending depletion over the area of production (Figure 4-B), very similar to the pattern on the acid extract propane map (Figure 3-B). Eh, pH conductivity, and magnetic susceptibility maps generally all show halo patterns around the area of production. Again, many of the indirect data maps display linear patterns that parallel structural trends.

$$
\text { (Figures 5, 6, 7) }
$$

\section{Wicape Prospect Area}

The Wicape Prospect Area is one of the largest blocks of unexplored land owned by the Fort Peck Tribes. This area is one of a number of prospect areas on the reservation that have 3D seismic surveys to guide exploration activities (Monson, Ewert, and Zeier, 1995). A time structure map on the Winnipeg Shale (Ordovician) is shown in Figure 5. The primary 3D seismic anomaly lies mainly in section 22 in the eastern part of the map. A secondary feature located 1.5 miles west lacks four-way closure on the time structure contours, but is included in 
the survey area. The large structural nose protruding from the northwest also has hydrocarbon potential but is not sampled because of the large areal extent. The Wicape Prospect Area is also located on the margin of a northwest-trending Landsat lineament zone. Within the area surveyed by surface exploration techniques, 210 collection locations were distributed along 18 east-west profiles.

Propane data maps for two direct techniques are shown in Figure 6. The head gas data, which correspond closely with production in the Palomino Field, clearly mark both the eastern and western seismic prospect (compare Figure 5 and Figure 6-A). The acid extract map shows a general halo anomaly around the eastern prospect, but has no distinctive patterns near the western prospect (compare Figure 5 and Figure 6-B). The soil gas survey produced ambiguous results, but with possible small anomalies over the seismic prospects. UV soil fluorescence map patterns show high values along the northwest-trending Poplar River and a strong northwest grain that may reflect geologic structure. Similar northwest patterns are present on many of the direct technique data maps.

Data maps for two indirect techniques are shown in Figure 7. Eh has larger negative values indicating a reducing environment over the eastern 3D seismic prospect (compare Figure 5 and Figure 7-A). The reducing environment is further indicated by high values of magnetic susceptibility arranged as a halo around the eastern prospect (compare Figure 5 and Figure 7-B). Maps of additional indirect data measurements, including soil microbes, iodine and $\mathrm{pH}$, have anomalies over the eastern prospect. Conductivity is inconclusive. The western 3D prospect that lacks four-way closure is generally not mapped by any of the indirect techniques. Also, many of the maps for indirect measurements do display northwest linear patterns that may reflect geologic structure.

\section{(Figures 8 and 9 )}

\section{Smoke Creek Area}

The very large Smoke Creek Area has no established oil production, but does have numerous potential hydrocarbon prospects. The prospects are all associated with a large aeromagnetic anomaly believed to be a major geologic structure in the area. This dominant feature is located at the intersection of regional Landsat lineament zones and has expression in a variety of stratigraphic and structure contour maps. In addition, curvilinears observed in Landsat tonal patterns are concentrated in the vicinity of the large aeromagnetic anomaly. All of this evidence has led to an interpretation (Monson and Shurr, 1993) of many hydrocarbon micro-seepage chimneys in the area. This view corresponds to a model proposed by Land in 1991. As a consequence, portions of the Smoke Creek Area were evaluated using surface exploration techniques that were most useful in the other two areas.

Because the total area is so large, magnetic susceptibility measurements were made in a reconnaissance survey. Almost 1200 observations were taken in a series of profiles that sampled the core of the major aeromagnetic anomaly, as well as the surrounding townships. Three areas of high susceptibility values emerged from this reconnaissance (Figure 8): Smoke Creek Core, Lobo West, and Site 26. The first two prospect areas have been surveyed in a preliminary way, but sampling is not yet sufficient to generate useful maps. However, the Site 26 Prospect Area has data grids comparable to those in the Palomino Oil Field and in the Wicape Prospect Area.

Monson, Shurr: 2002

page 5 
Magnetic susceptibility values contoured in the Site 26 Prospect Area are shown in Figure 9-A. The anomaly is on the southeastern end of a structural nose documented in a 3D seismic survey. The magnetic susceptibility anomaly located in the northwest quarter of section 15 is also well mapped by propane contours on soil gas measurements (Figure 9-B) and on head gas measurements. No other direct detection techniques were employed. Indirect techniques had a wide range of utility: soil microbes and iodine anomalies generally correlate well with direct measurements, conductivity displays a halo, but Eh and $\mathrm{pH}$ are inconclusive.

Much work remains on going in the Smoke Creek Area. Reconnaissance magnetic susceptibility data will be further evaluated. Measurements of the magnetic field along three profile lines will be integrated with other data and interpretations. And, curvilinear features mapped on Landsat images will be closely compared with a variety of data sets. All of this activity is aimed at evaluating the curvilinears as signatures for diagenetic chimneys and at further defining and refining potential hydrocarbon prospects.

\section{Su m m a ry}

A summary of map observations in each of the three study areas is presented in Table 2. Surface exploration techniques are arranged in an approximate order of usefulness. Head gas emerges as the most functional of the direct techniques. Acid extract and thermal desorption measurements are also generally useful. Soil gas works well if sampling density is sufficient. UV soil fluorescence is of limited utility. Among the indirect observation techniques, soil microbial and iodine data are most useful. Eh, $\mathrm{pH}$, and conductivity also show some utility. Magnetic susceptibility appears to be helpful, but is also being further extensively evaluated.

\section{$(\mathrm{Tab} \mid \mathrm{e} 2)$}

\section{HYDROCARBON FLUX SOURCES}

Anomaly patterns in surface exploration measurements reflect the geometry of the diagenetic chimneys that form over discrete sources of hydrocarbon flux. Thus, a single and simple source might be expected to have an apical or halo anomaly pattern and a linear pattern is probably associated with a fault or fracture system. The three study areas have three distinctive flux sources. In the Palomino Oil Field, the single source is small and fairly simple. In the Wicape Prospect Area, the double flux sources are larger but are still fairly simple. In the Smoke Creek Area, there is a large and complex field of multiple and overlapping sources.

In addition to the geometry of the flux source, anomaly patterns also reflect the history of hydrocarbon migration. For example, depletion patterns observed in the Palomino Oil Field indicate a fairly rapid modification of the surface signature as production reduces the flux of hydrocarbon gases. This may be the result of reductions in reservoir pressure. In contrast, both the Palomino Oil Field and Wicape Prospect Area contain diagenetic chimneys that suggest currently active gas flux. The large and complex Smoke Creek Area probably represents a mixture of multi-stage flux histories and may contain fossil as well as active sources. 


\section{CONCLUSIONS}

Surface exploration techniques clearly document hydrocarbon seepage on the Fort Peck Reservation. Among the direct detection techniques, head gas and acid extract methods are most useful in mapping production and potential prospects; thermal desorption was only tested at Palomino Oil Field and correlated well to production; and the soil gas method has less understandable utility. Indirect techniques that are useful include soil microbial, iodine, and Eh soil analyses. UV soil fluorescence, $\mathrm{pH}$, and conductivity are all relatively inconclusive. Evaluation continues on the utility of magnetic susceptibility.

Hydrocarbon seepage has been assessed in three separate study areas on the reservation. Palomino Oil Field is a small area with established oil production. The Wicape Prospect Area is larger and has two 3D seismic prospects. The Smoke Creek Area is very large and appears to have several potential prospects. This sequence of three study areas provides a spectrum of hydrocarbon flux sources that range from small and simple to large and complex. In general, surface exploration techniques are effective aids in mapping production and prospects in all three areas of the reservation.

\section{REFERENCES CITED}

Land, J.P., 1991, A comparison of micromagnetic and surface geochemical survey results, Association of Petroleum Geochemical Explorationists Bulletin, v. 7, p. 12-35.

Monson, L.M., 1995, Fort Peck Reservation oil summary, part I: reservoirs, production, and reserves, in L.D. Hunter and R. A. Schalla, eds., Seventh international Williston Basin symposium: Montana Geological Society, p. 253-264.

Monson, L.M., 2000, Phase I interim report 1, Fort Peck Reservation assessment of hydrocarbon seepage: Semi-annual Technical Progress Report, Department of Energy Grant Award \#DE-FG26-00BC15192.

Monson, L.M., 2001, Phase I report 2, Fort Peck Reservation assessment of hydrocarbon seepage: Semi-annual Technical Progress Report, Department of Energy Grant Award \#DE-FG26-00BC15192.

Monson, L.M., 2002, Phase II report 3, Fort Peck Reservation assessment of hydrocarbon seepage: Semi-annual Technical Progress Report, Department of Energy Grant Award \#DE-FG26-00BC15192.

Monson, L.M., W. Ewert, R. Zeier, 1995, Fort Peck Reservation oil summary, part II: exploration opportunities, in L.D. Hunter and R. A. Schalla, eds., Seventh international Williston Basin symposium: Montana Geological Society, p. 265-278.

Monson, L.M., and G.W. Shurr, 1993, Remote sensing applications in the assessment of natural resources on the Fort Peck Reservation, Montana, in Proceedings of the ninth thematic conference on geologic remote sensing: Environmental Research Institute of Michigan, v. 1, p. 431-443. 
Shurr, G.W., and L.M. Monson, 1995, Tectonic setting and paleotectonic history of Fort Peck Reservation in northeastern Montana, in L.D. Hunter and R. A. Schalla, eds., Seventh international Williston Basin symposium: Montana Geological Society, p. 11-22.

\section{FIGURE CAPTIONS}

Figure 1. Location map for Fort Peck Reservation and the three study areas located on the reservation.

Figure 2. Nisku Formation (Devonian) subsea structure map in the Palomino Oil Field study area.

Figure 3. Examples of maps prepared from direct surface exploration techniques employed in the Palomino Oil Field: (a) head gas; (b) acid extract.

Figure 4. Examples of maps prepared from indirect surface exploration techniques employed in the Palomino Oil Field: (a) iodine; (b) microbial.

Figure 5. Winnipeg Shale (Ordovician) time structure map in the Wicape Prospect Area.

Figure 6. Examples of maps prepared from direct surface exploration techniques employed in the Wicape Prospect Area: (a) head gas; (b) acid extract.

Figure 7. Examples of maps prepared from indirect surface exploration techniques employed in the Wicape Prospect Area: (a) soil Eh; (b) magnetic susceptibility.

Figure 8. Magnetic susceptibility values mapped in the Smoke Creek Area.

Figure 9. Examples of maps prepared from surface exploration techniques in the potential prospect area, Site 26, of the Smoke Creek Area: (a) magnetic susceptibility; (b) soil gas. 
Table 1: Surface Exploration Methods Employed

\begin{tabular}{|c|c|c|}
\hline Technique & $\begin{array}{l}\text { Sample } \\
\text { Depth }\end{array}$ & $\begin{array}{c}\text { Theoretical } \\
\text { Basis }\end{array}$ \\
\hline \multicolumn{3}{|l|}{ Direct } \\
\hline Head Gas & $61-91 \mathrm{~cm}$ & Water dissolves adsorbed light gases. \\
\hline Acid Extract & $15-30 \mathrm{~cm}$ & Acid frees occluded light gases. \\
\hline Thermal Desorption & $15 \mathrm{~cm}$ & Heat frees adsorbed light gases. \\
\hline Soil Gas & $61-91 \mathrm{~cm}$ & Microseepage of light gases. \\
\hline UV Soil Fluorescenct & $15-30 \mathrm{~cm}$ & Fracture-migrated medium weight gases. \\
\hline \multicolumn{3}{|l|}{ Indirect } \\
\hline Soil Microbial & $15-22 \mathrm{~cm}$ & Hydrocarbon-feeding bacteria in soil. \\
\hline Iodine & $3 \mathrm{~cm}$ & Hydrocarbons pull iodine from soil or air. \\
\hline $\mathrm{Eh}$ & $61-91 \mathrm{~cm}$ & Reducing (low Eh) environment above seep. \\
\hline $\mathrm{pH}$ & $61-91 \mathrm{~cm}$ & Relatively higher $\mathrm{pH}$ associated with seep. \\
\hline Conductivity & $61-91 \mathrm{~cm}$ & Salts precipitated in high $\mathrm{pH}$ soils. \\
\hline Magnetic Susceptibil: & $15-30 \mathrm{~cm}$ & Easily magnetized ferrous minerals precipitated in low Eh environ \\
\hline
\end{tabular}


Table 2: Comparative Analysis of Surface Exploration Methods

Technique

\section{Direct}

Head Gas

Acid Extract

Thermal Desorption

Soil Gas

UV Soil Fluorescence

Indirect

Soil Microbial

Iodine

Eh

$\mathrm{pH}$

Conductivity

Magnetic Susceptibility

Palomino

Wicape

Smoke Creek

Best correspondence

Depletion signature

Partial correspondence

Depletion signature

Inclusive

Depletion signature

Depletion signature

Halo

Halo

Halo

Halo
Corresponds with prospects

Halo on east prospects

Not surveyed

Possible halos

No correspondence

High on east prospect

High on east prospect

High on east prospect

Possible halo on east

No correspondence

Halo on east prospect
Corresponds

Not surveyed

Not surveyed

Corresponds

Not surveyed

Good correspondence

Good correspondence

Inclusive

Inclusive

Halo

Defines prospect 


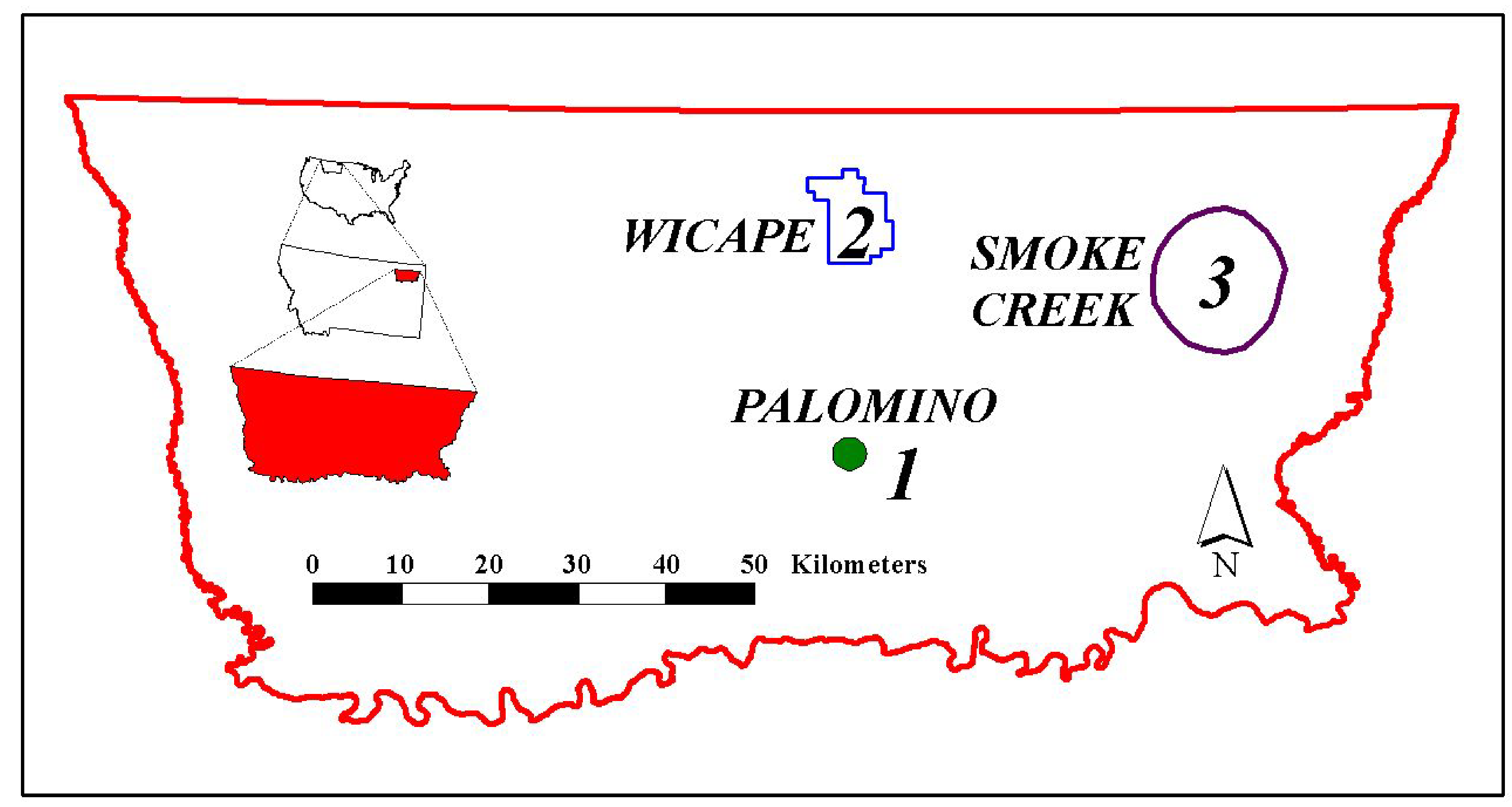

Figure 1. Location of Fort Peck Reservation, northeast Montana, U.S. with surface hydrocarbon sample areas: 1 - Palomino Oil Field, 2 - Wicape 3D Prospect Area, 3 - Smoke Creek AeroMag Anomaly. 


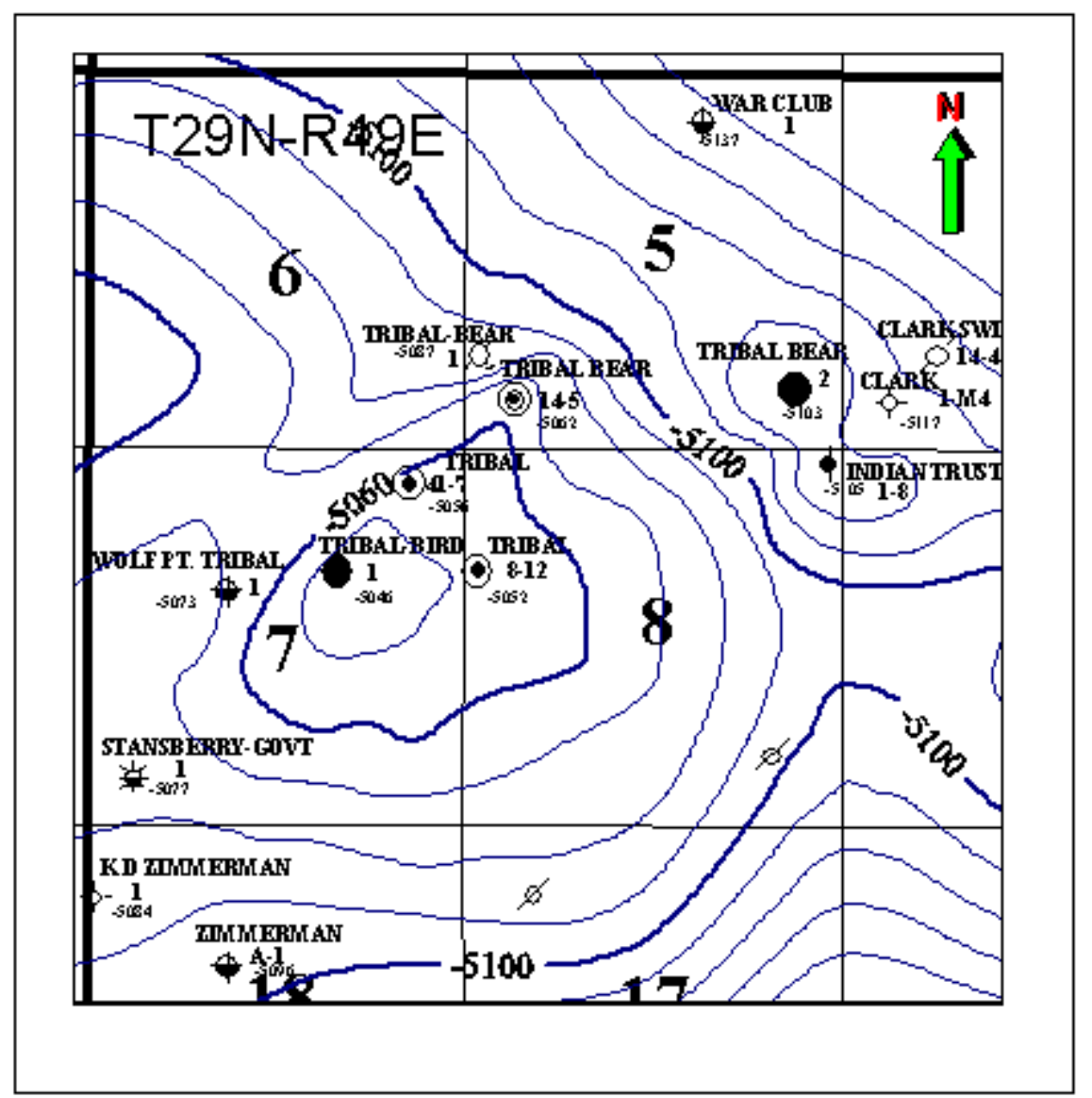

Figure 2: N1sku subsea structure at Palomino Oil Field. C.I. $=10 \mathrm{ft}$. 


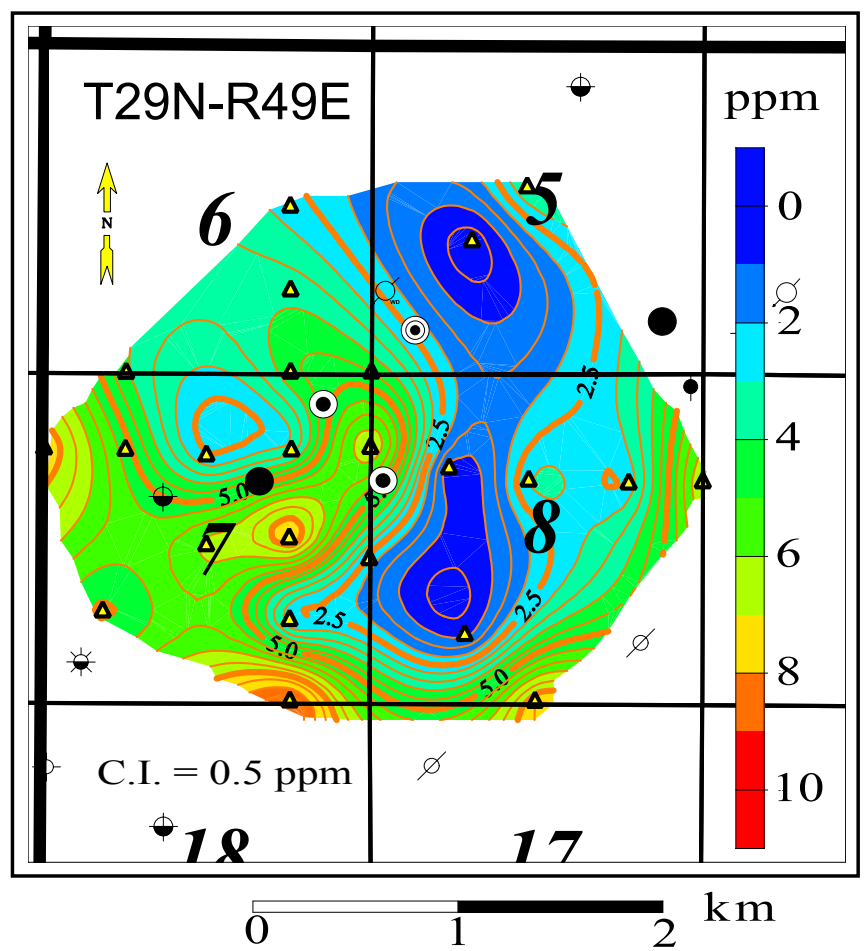

Figure 3-A. Palomino soil Head Gas.

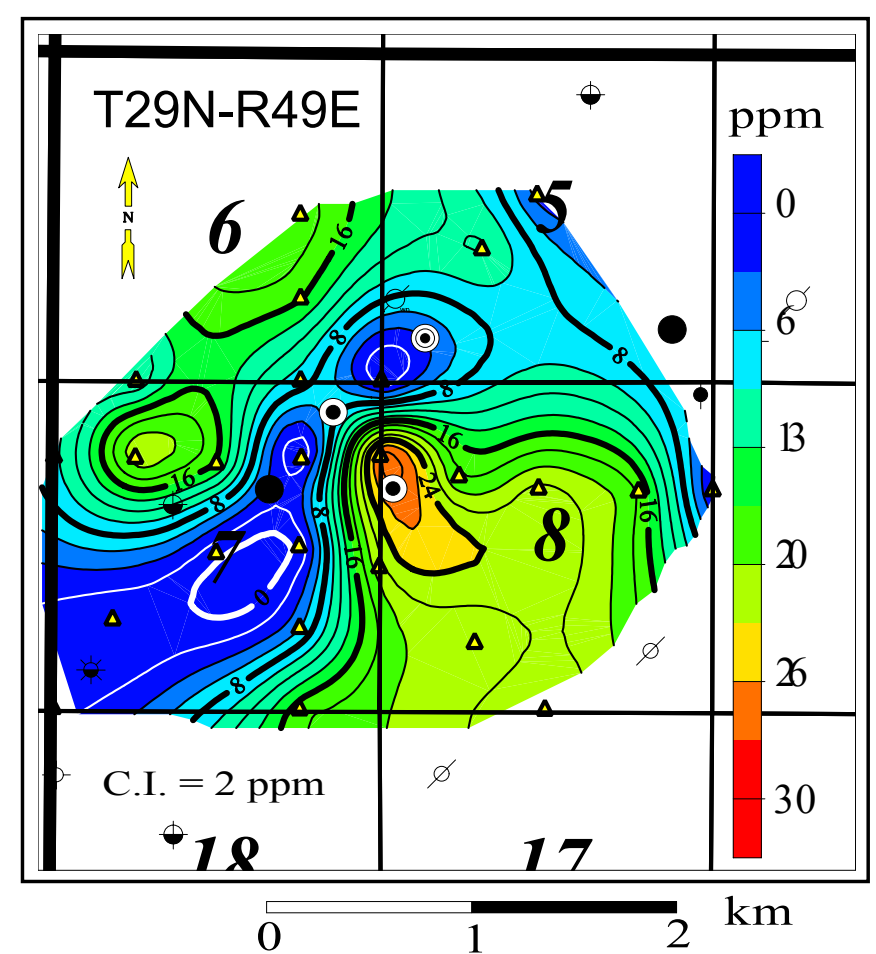

Figure 3-B. Palomino soil Acid Extract Gas. 


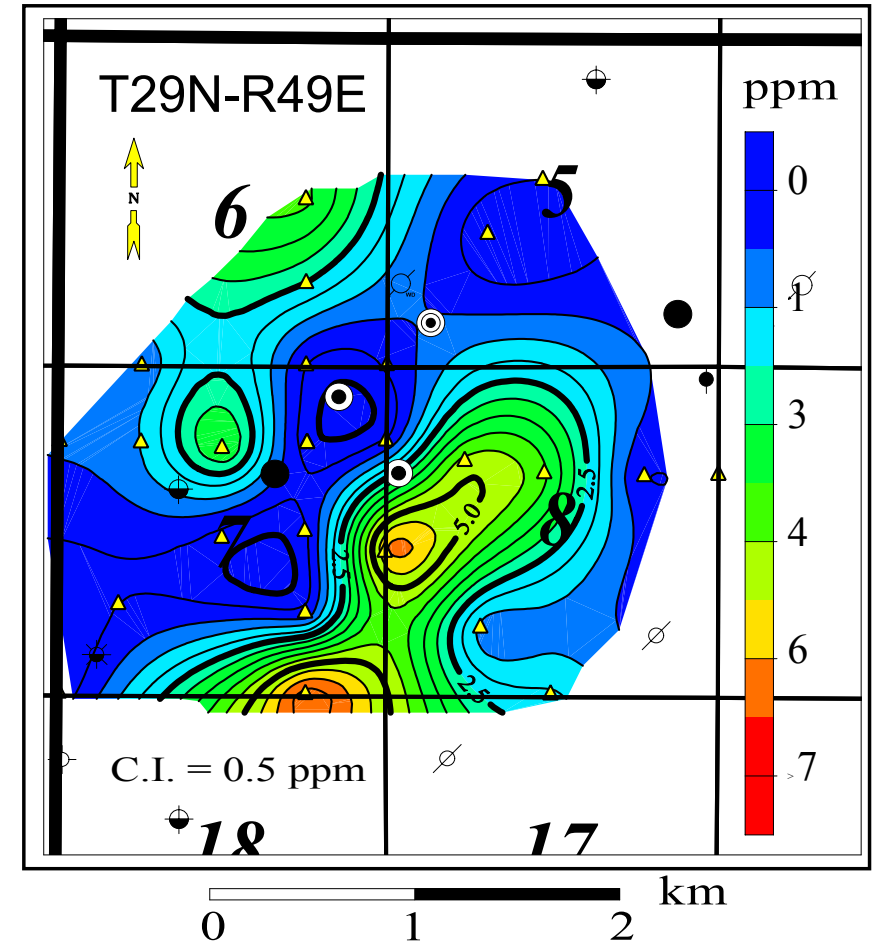

Figure 4-A. Palomino soil Iodine.

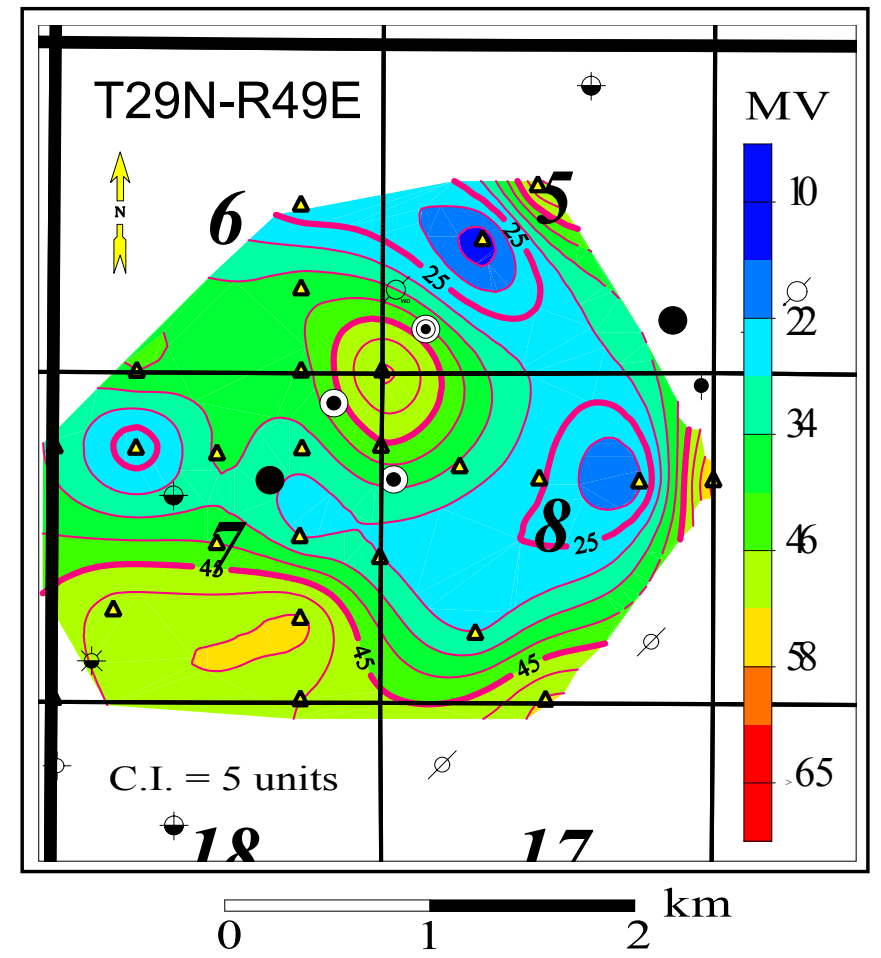

Figure 4-B. Palomino soil Microbial count. 


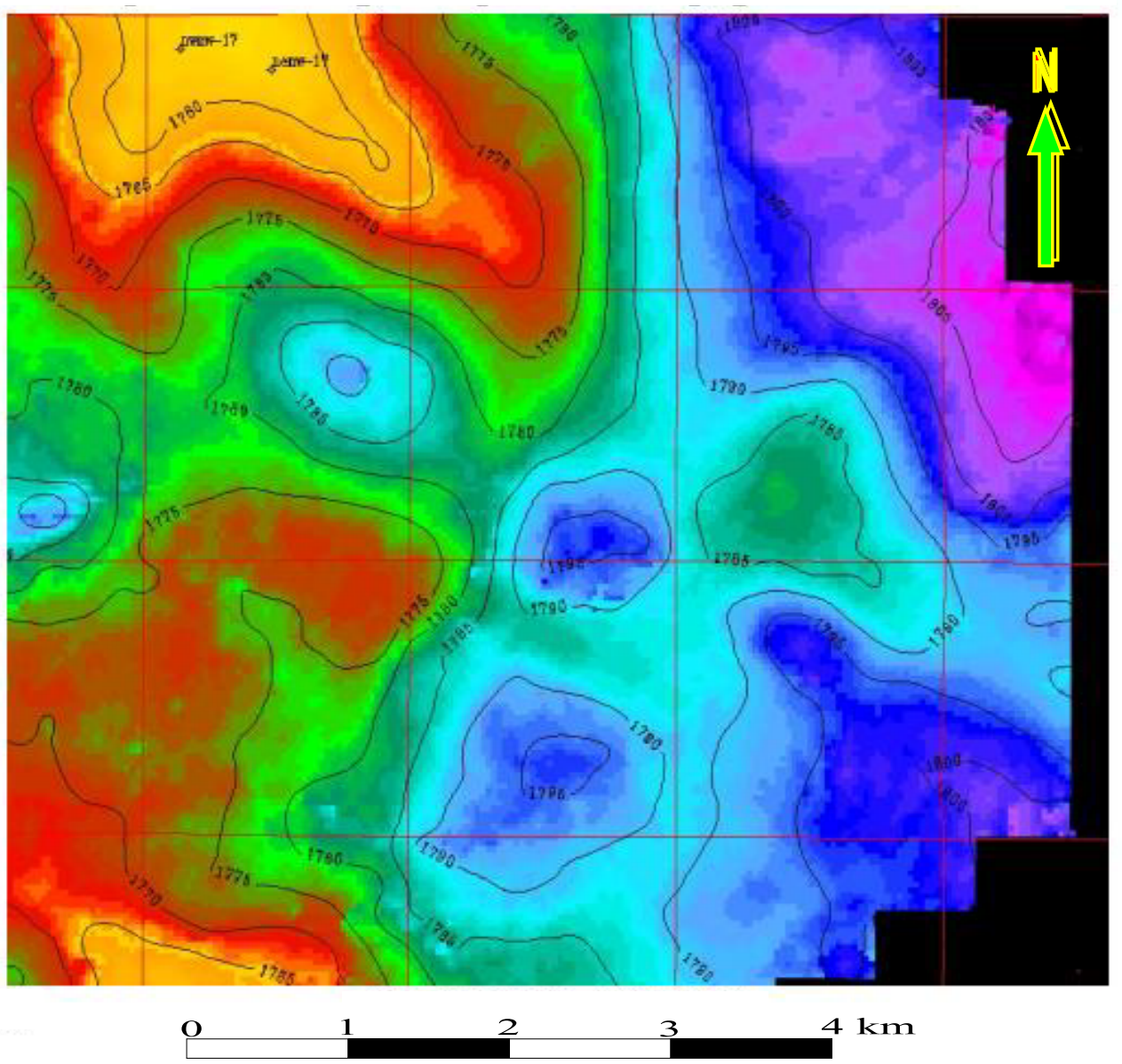

Figure 5. Winnipeg Shale time structure, Wicape 3D Prospect Area. 


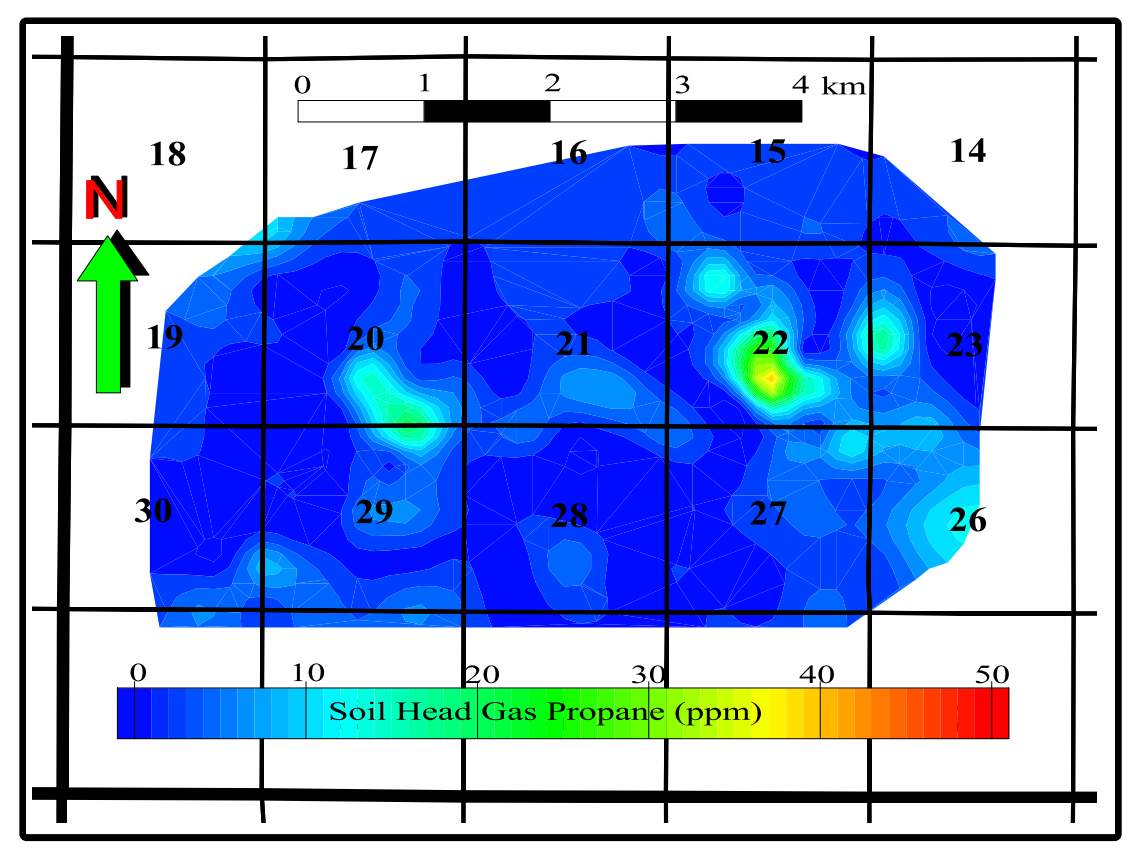

Figure 6-A. Wicape Area Head Gas Propane. C.I. $=2$ ppm.

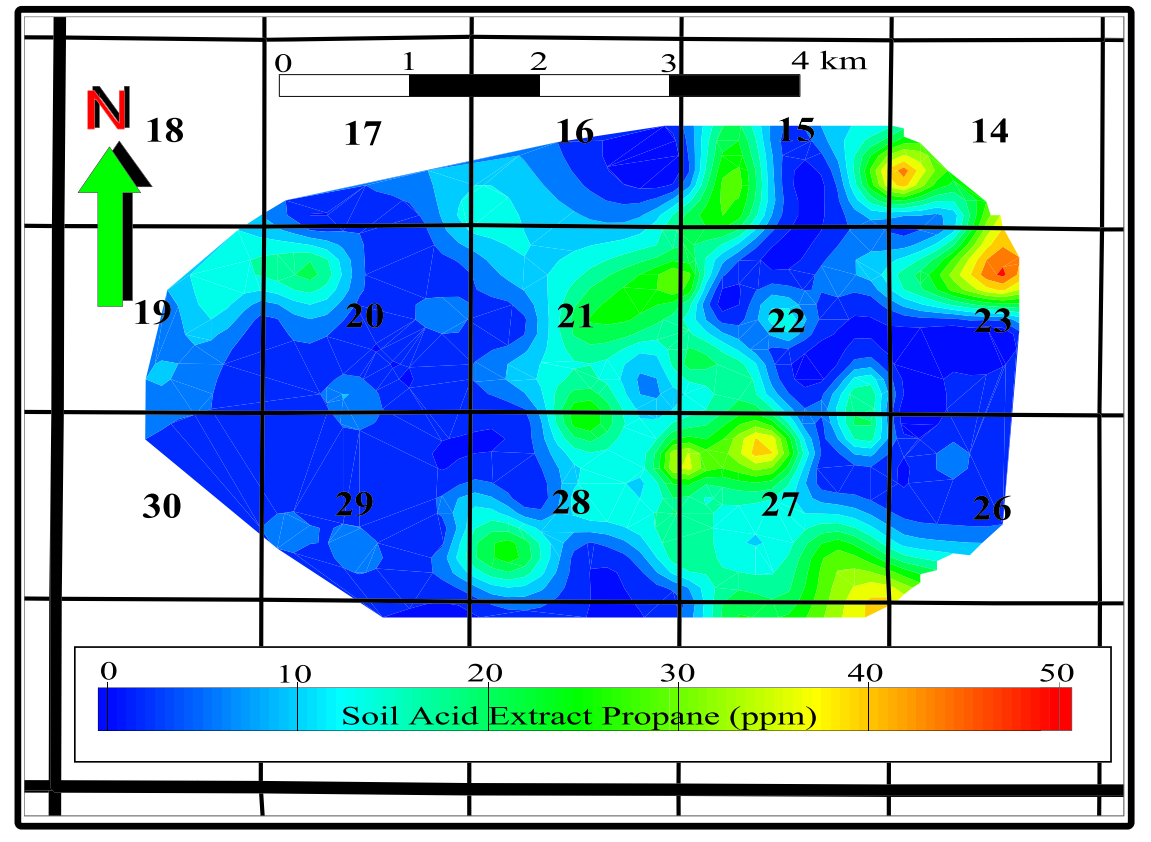

Figure 6-B. Wicape Area Acid Extract Propane. C.I. $=4$ ppm. 




Figure 7-A. Wicape Area soil Eh. C.I. $=50$ millivolts.

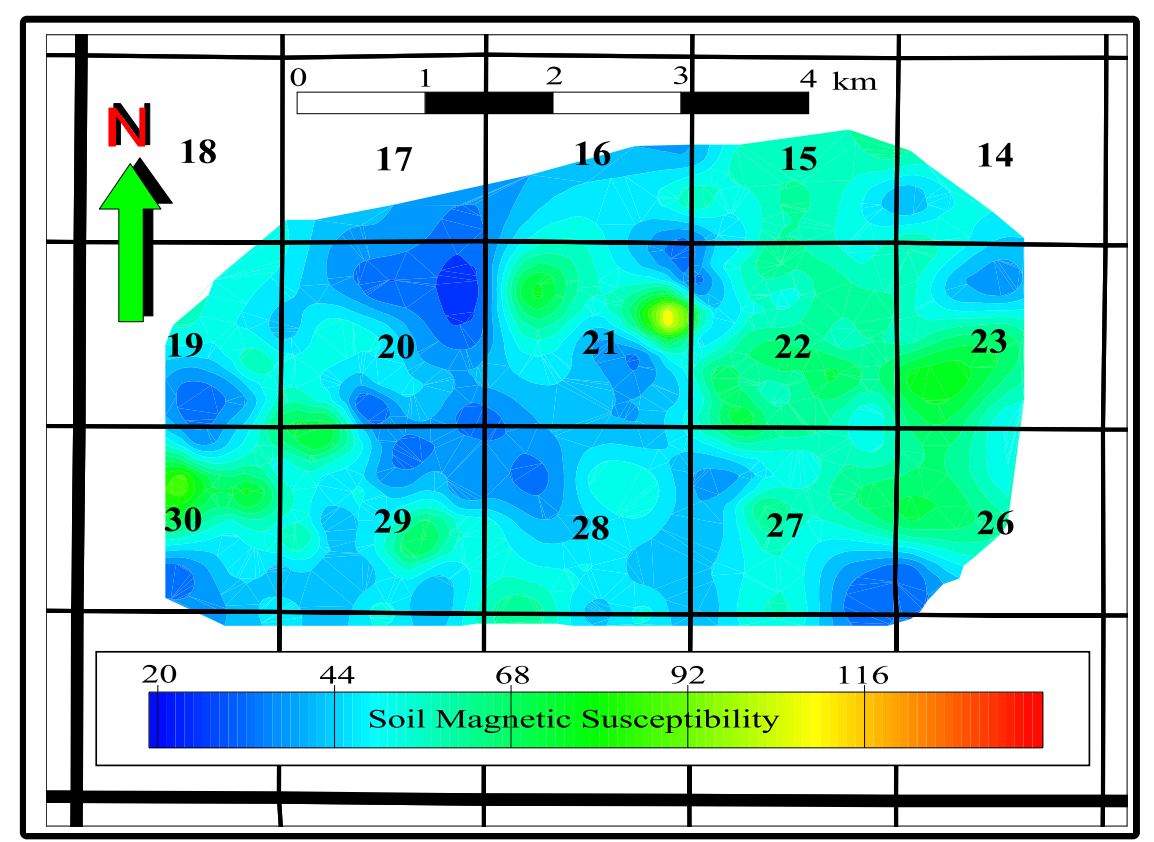

Figure 7-B. Wicape Area soil Magnetic Susceptibility. C.I. $=5 \operatorname{cgs} x$ 10e-6. 


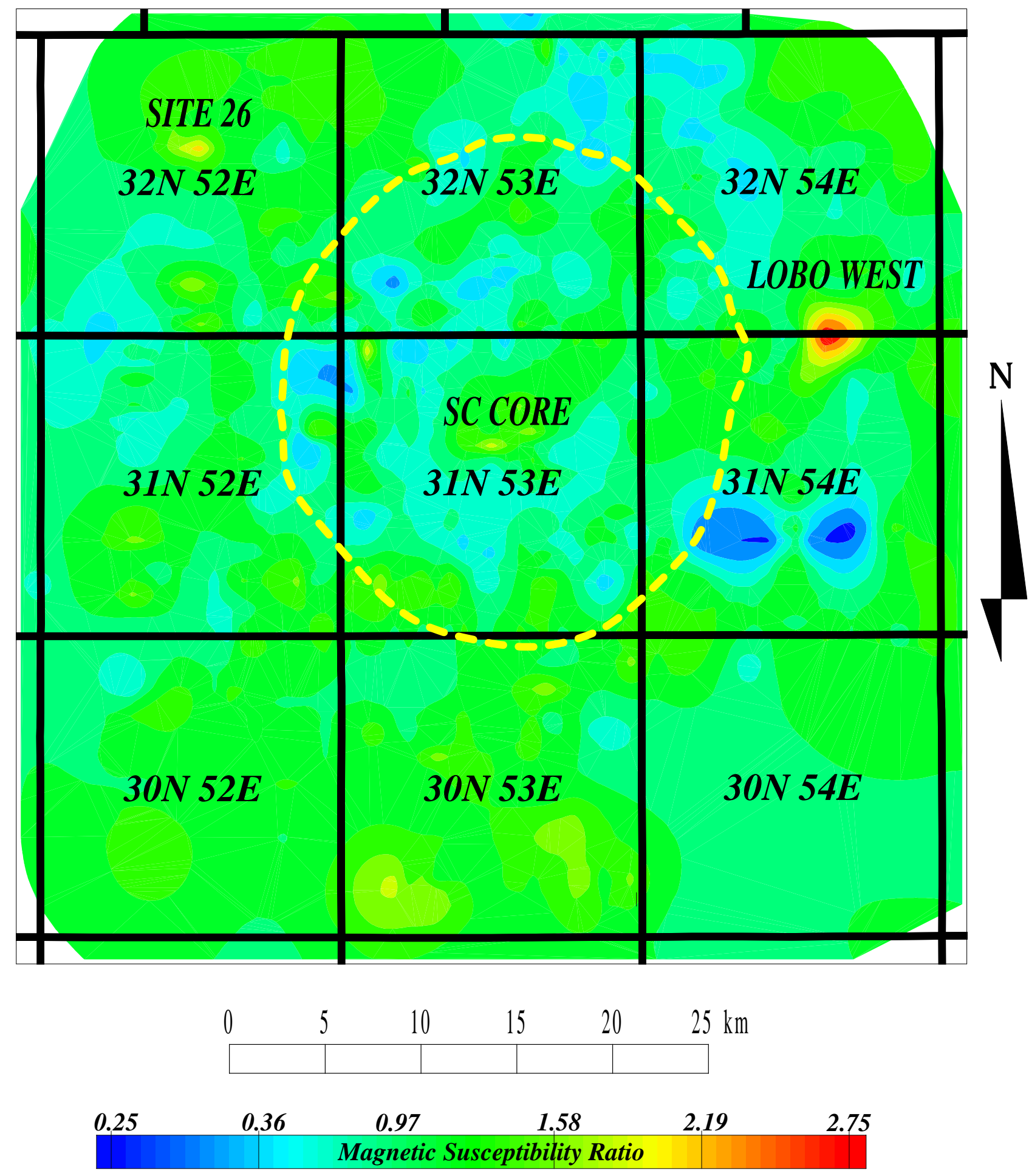

Figure 8. Smoke Creek Area soil Magnetic Susceptibility Ratio, with AeroMag Anomaly (dashed line) and three anomalous areas: Site 26, SC Core, and Lobo West. 

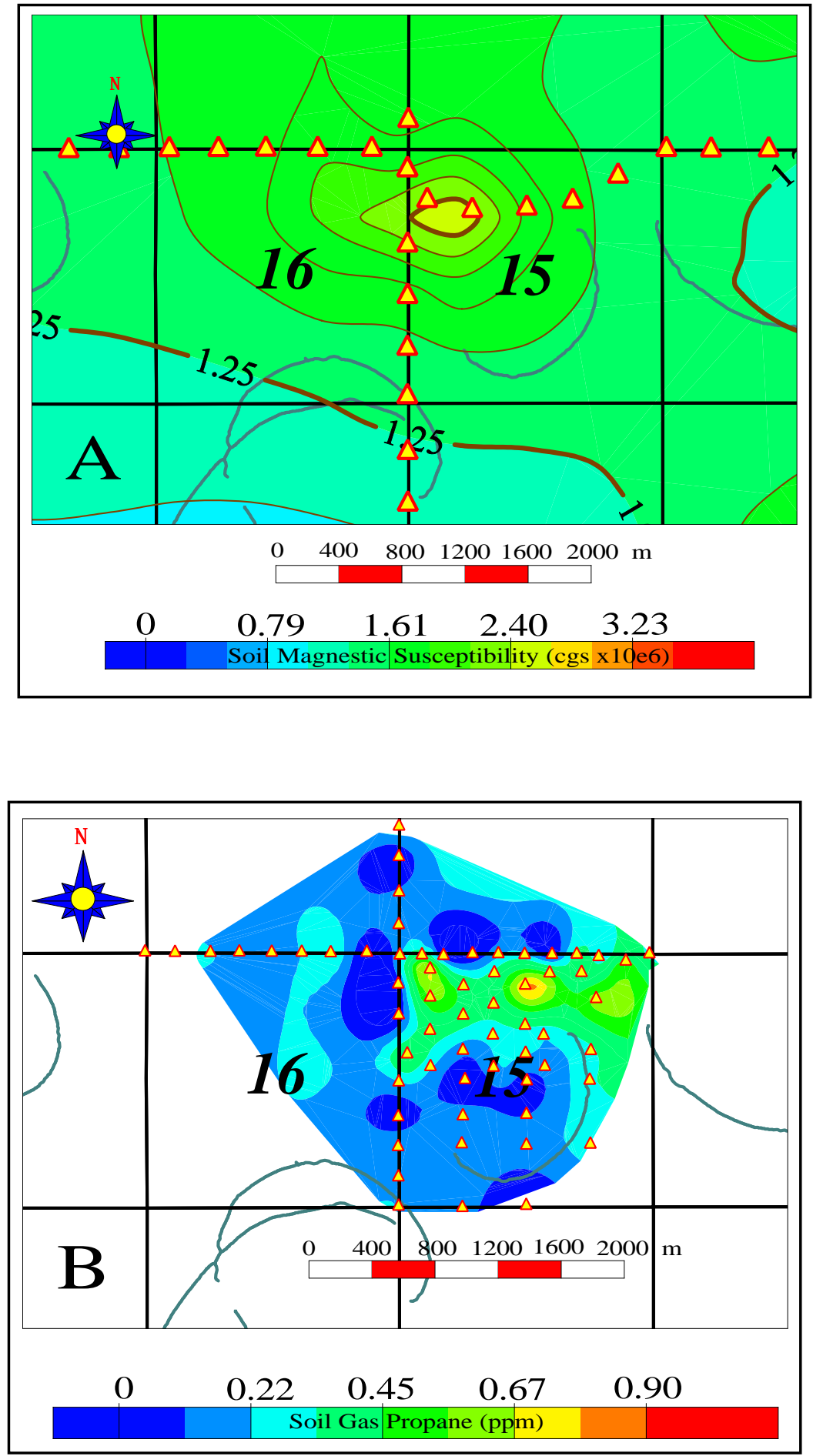

Figure 9. A - Site 26 Soil Magnetic Susceptibility, C.I. $=0.25 \mathrm{cgs}$. B - Site 26 Soil Gas Propane, C.I. $=0.1$ ppm. Landsat curvilinears plotted in gray arcs. Sample sites shown as yellow triangles. 